\title{
Imported malaria
}

\author{
Merlin L Willcox general practitioner ${ }^{1}$, Jill Mant paediatric specialist registrar ${ }^{2}$, Tim O'Dempsey \\ consultant in tropical medicine ${ }^{3}$
}

${ }^{1}$ Department of Primary Care Health Sciences, University of Oxford, Oxford OX1 2EP, UK; ${ }^{2}$ Department of Paediatrics, Luton Hospital, Luton, UK; ${ }^{3}$ Liverpool School of Tropical Medicine, Liverpool, UK

This is one of a series of occasional articles highlighting conditions that may be more common than many doctors realise or may be missed at first presentation. The series advisers are Anthony Harnden, university lecturer in general practice, Department of Primary Health Care,

University of Oxford, and Richard Lehman, general practitioner, Banbury. To suggest a topic for this series, please email us at easilymissed@bmj.com.

A 19 year old student phoned an official health service telephone helpline with a 10 day history of aching legs, vomiting, diarrhoea, and abdominal pain. She mentioned a recent trip to Uganda but was reassured and told she had "flu." The next day her boyfriend took her to see her doctor, where she mentioned general malaise, tiredness, and occasional nausea; the doctor diagnosed a viral illness and advised her to keep taking paracetamol. Three days later a friend found her dead in bed in her university halls of residence. The coroner recorded death due to cerebral malaria. ${ }^{1}$

\section{What is malaria?}

Malaria is an infection caused by protozoa of the genus Plasmodium. Five species infect humans (P falciparum, $P$ vivax, $P$ ovale, $P$ malariae, and $P$ knowlesi). Most of the fatal cases are caused by $P$ falciparum.

\section{Why is malaria missed in non-endemic countries?}

As illustrated by the case described here, the symptoms of malaria are non-specific and can easily be mistaken for a viral illness such as influenza, unless clinicians think to ask patients whether they have travelled abroad.

A retrospective observational study of 191 deaths due to malaria in the United Kingdom from 1987 to 2006 found that the case fatality was inversely related to incidence, suggesting that cases were more easily missed by clinicians unaccustomed to seeing this disease. ${ }^{4}$ A retrospective series of 39 cases of malaria diagnosed in Sheffield from 2000 to 2005 found that eight of these patients had presented to health professionals with symptoms of malaria but were not immediately referred to hospital or for a diagnostic test, suggesting that the diagnosis of malaria had not been considered. ${ }^{6}$ A retrospective case review of 211 children admitted to hospital with malaria in east London found that 114 had initially presented to their doctor, but malaria was suspected at the first visit in only $32 \%$ of these, and diagnosis was delayed in $53 \%$, by one to 14 days. ${ }^{7}$

\section{Why does this matter?}

If untreated, malaria can be rapidly fatal, particularly in non-immune patients. Delay in diagnosis is associated with an increased risk of severe malaria and death. ${ }^{58}$ The overall case fatality rate from malaria in the United Kingdom is $0.73 \%,{ }^{4}$ but for cases with signs of severe malaria (box) this may reach $10-20 \% .^{9}$ Severe complications and death may occur within 24-48 hours of onset of symptoms. ${ }^{10}{ }^{11}$ Early diagnosis and appropriate treatment are therefore crucial.

\section{How is malaria diagnosed? Clinical}

Question anyone presenting with a history of fever or flu-like symptoms about travel to malaria endemic countries within the past year. Investigate urgently those returning from a malaria endemic area, regardless of whether they have taken malaria prophylaxis. Intermittent fever may be a feature of malaria, so temperature may be normal at the time of examination. A case series of 482 patients in the United States found that half of adult patients were not febrile when they presented, although most had a history of fever. ${ }^{12}$ Other common symptoms include vomiting, diarrhoea, headache, and myalgia. ${ }^{5}{ }^{12}$ Most patients with $P$ falciparum present within six months of returning from abroad, although later presentations may occur. The box shows the features of severe disease. 


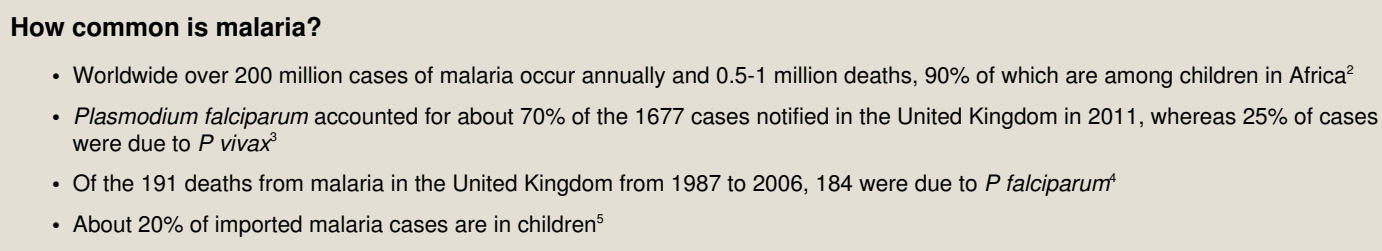

\section{Definition of severe malaria ${ }^{9}$}

In patients with Plasmodium falciparum asexual parasitaemia and no other obvious cause of symptoms, severe malaria is defined by one or more of the following features:

\section{Clinical features}

Impaired consciousness or coma from which patients cannot be roused

Prostration - that is, generalised weakness such that that patients cannot sit up unaided

Failure to feed

Multiple convulsions-more than two episodes in 24 hours

Deep breathing, respiratory distress (acidotic breathing)

Circulatory collapse or shock, systolic blood pressure $<70 \mathrm{~mm} \mathrm{Hg}$ in adults and $<50 \mathrm{~mm} \mathrm{Hg}$ in children

Clinical jaundice plus evidence of other vital organ dysfunction

Haemoglobinuria

Abnormal spontaneous bleeding

Pulmonary oedema (radiological)

\section{Laboratory findings}

Haematology

Severe normocytic anaemia (haemoglobin level $<50 \mathrm{~g} / \mathrm{L}$, packed cell volume $<15 \%$ )

Hyperparasitaemia ( $>2 \%$ or $100000 / \mu \mathrm{L}$ in areas of low intensity of transmission; $>5 \%$ or $250000 / \mu \mathrm{L}$ in areas of high and stable intensity of transmission)

\section{Biochemistry}

Hypoglycaemia (blood glucose level $<2.2 \mathrm{mmol} / \mathrm{L}$ or $<40 \mathrm{mg} / \mathrm{dL}$ )

Renal impairment (serum creatinine level $>265 \mu \mathrm{mol} / \mathrm{L}$ )

Metabolic acidosis (plasma bicarbonate level $<15 \mathrm{mmol} / \mathrm{L}$ )

Hyperlactataemia (lactate $>5 \mathrm{mmol} / \mathrm{L}$ )

Urine

Haemoglobinuria

\section{Investigations}

It is preferable to refer all patients with suspected malaria to hospital immediately for further investigation because of the risk of rapid progression of falciparum malaria. However, if the patient is relatively well and it is possible to obtain results rapidly (the same day), it may be reasonable to investigate in a primary care setting. This calls for some clinical judgment. If the risk of malaria is low and the patient is not severely ill, outpatient testing with next day results may be acceptable, but the patient should then be advised to reconsult rapidly if there is any worsening of symptoms.

The clinician should request an urgent full blood count and "malaria thick and thin films" (both on the same EDTA sample). Although microscopy is the standard diagnostic method, low density infection may be missed, ${ }^{13}$ particularly if microscopists are inexperienced or if patients have taken an antimalarial or an antibiotic with antimalarial activity. Therefore, if the first slide gives a negative result, films should be repeated after 12-24 hours, and again after another 24 hours. The likelihood of malaria is low if experienced microscopists find three consecutive negative blood film results. ${ }^{14}$

In the United Kingdom some haematology laboratories may also be able to perform a rapid diagnostic test. These tests are based on detection of parasite antigens or enzymes; a recent Cochrane review found that the sensitivity and specificity of the most common rapid diagnostic tests were both $95 \%$, compared with microscopy. ${ }^{15}$ Rapid diagnostic tests are useful in increasing speed of diagnosis, even in non-endemic countries ${ }^{16}$ and, if available, can be used as an adjunct to microscopy, although they cannot replace it. All positive malaria test results should be telephoned immediately to the requesting doctor and communicated by the doctor to the patient. ${ }^{14}$.

Thrombocytopenia is common in acute malaria, and, if otherwise unexplained, may be an important clue even if the blood film has been reported as negative. A prospective study looking at returning travellers with fever found that leucocyte counts $<10 \times 10^{9} / \mathrm{L}$, platelet counts $<150 \times 10^{9} / \mathrm{L}$, and haemoglobin levels $<120 \mathrm{~g} / \mathrm{L}$ were all associated with an increased probability of malaria. Thrombocytopenia was the best predictor, with a positive likelihood ratio of $11 .^{17}$

\section{How is malaria managed?}

Seek expert advice on treatment, particularly if there are signs of complications. In the primary care setting, if there are any signs of severe malaria, refer the patient to hospital as an emergency and treat any complications (for example, shock, hypoglycaemia, convulsions) while awaiting transfer.

Most patients with falciparum malaria need admission to hospital, although recent evidence has suggested that a small 
selected group with uncomplicated falciparum malaria can be treated safely as outpatients. ${ }^{18} 19$ Those with uncomplicated non-falciparum infections can usually be managed as outpatients provided they are able to take oral drugs. Mixed infections can occur and $P$ falciparum may be missed or misdiagnosed. Therefore it is sensible to have a low threshold for admission and to advise all those treated as outpatients to seek further medical attention urgently if they deteriorate. It is also advisable to review all patients with malaria 1-2 weeks after completion of treatment. ${ }^{18} 19$

Because of the risk of increasing drug resistance, the World Health Organization now recommends that uncomplicated $P$ falciparum malaria should be treated with artemisinin combination therapies. ${ }^{9}$ Recent studies have proved that intravenous artesunate is more effective than quinine for the treatment of severe malaria, ${ }^{20}{ }^{21}$ but UK guidelines still recommend quinine because artesunate is unlicensed in the European Union. ${ }^{14}$ These guidelines are, however, currently under review. Chloroquine is usually effective for non-falciparum malarias; however, chloroquine resistant $P$ vivax is increasingly prevalent in some areas (for example, Indonesia, Peru, and Oceania). ${ }^{9}$ In addition, patients with $P$ vivax or $P$ ovale infections should have their glucose 6 phosphate dehydrogenase (G6PD) status checked and, unless significantly G6PD deficient, should also be treated with an appropriate course of primaquine to reduce the likelihood of relapses. ${ }^{22}$

UK guidelines for malaria treatment ${ }^{14}$ and a useful management algorithm are available at www.hpa.org.uk/Topics/InfectiousDiseases/ InfectionsAZ/Malaria/Guidelines/mala20guidelinesTreatment/.

Contributors: MW wrote the first draft of the article, which was revised by the coauthors. All authors read and approved the final manuscript. MW is guarantor of the paper.

Competing interests: All authors have completed the ICMJE uniform disclosure form at http://www.icmje.org/coi_disclosure.pdf (available on request from the corresponding author) and declare: no support from any organisation for the submitted work; no financial relationships with any organisations that might have an interest in the submitted work in the previous three years, no other relationships or activities that could appear to have influenced the submitted work.

Provenance and peer review: Not commissioned; externally peer reviewed.

Patient consent not required (patient anonymised, dead, or hypothetical).

1 Anon. Student died of Malaria after being diagnosed with flu. Secondary student died of malaria after being diagnosed with flu. Mail Online 2007 Jan 10. www.dailymail.co.uk/ news/article-427932/Student-died-Malaria-diagnosed-flu.html\#.

2 World Health Organization. World malaria report 2011. WHO, 2011.

3 Health Protection Agency. Imported malaria cases and deaths, United Kingdom:

1992-2011. Secondary imported malaria cases and deaths, United Kingdom: 1992-2011. 2012. www.hpa.org.uk/Topics/InfectiousDiseases/InfectionsAZ/Malaria/ EpidemiologicalData/malaEpi10CasesandDeaths/.
4 Checkley AM, Smith A, Smith V, Blaze M, Bradley D, Chiodini PL, et al. Risk factors for mortality from imported falciparum malaria in the United Kingdom over 20 years: an observational study. BMJ 2012;344:bmj.e2116.

5 Ladhani S, Aibara RJ, Riordan FA, Shingadia D. Imported malaria in children: a review of clinical studies. Lancet Infect Dis 2007;7:349-57.

6 Green ST, Jary HR, Darton TC. Missed opportunities to diagnose Plasmodium falciparum malaria: results of a regional service evaluation. $J$ Infect 2009;58:172-3.

7 Ladhani S, El Bashir H, Patel VS, Shingadia D. Childhood malaria in East London. Pediatr Infect Dis J 2003;22:814-9.

8 Dubos F, Dauriac A, El Mansouf L, Courouble C, Aurel M, Martinot A. Imported malaria in children: incidence and risk factors for severity. Diagn Microbiol Infect Dis 2010;66:169-74.

9 World Health Organization. Guidelines for the treatment of malaria. 2 edn. WHO, 2010.

10 Centers for Disease Control and Prevention. Domestic refugee health guidelines: malaria secondary domestic refugee health guidelines: malaria. 2012. www.cdc.gov/ immigrantrefugeehealth/guidelines/domestic/malaria-guidelines-domestic.html.

11 Newman RD, Parise ME, Barber AM, Steketee RW. Malaria-related deaths among U.S. travelers, 1963-2001. Ann Intern Med 2004;141:547-55.

12 Svenson JE, MacLean JD, Gyorkos TW, Keystone J. Imported malaria. Clinical presentation and examination of symptomatic travelers. Arch Intern Med 1995:155:861-8.

13 Batwala V, Magnussen P, Nuwaha F. Are rapid diagnostic tests more accurate in diagnosis of plasmodium falciparum malaria compared to microscopy at rural health centres? Malar J 2010;9:349.

14 Lalloo DG, Shingadia D, Pasvol G, Chiodini PL, Whitty CJ, Beeching NJ, et al. UK malaria treatment guidelines. J Infect 2007;54:111-21.

15 Abba K, Deeks JJ, Olliaro P, Naing CM, Jackson SM, Takwoingi Y, et al. Rapid diagnostic tests for diagnosing uncomplicated $\mathrm{P}$. falciparum malaria in endemic countries. Cochrane Database Syst Rev 2011;(7):CD008122.

16 Rossi I, D'Acremont V, Prod'Hom G, Genton B. Safety of falciparum malaria diagnostic strategy based on rapid diagnostic tests in returning travellers and migrants: a retrospective study. Malar J 2012;11:377.

17 D'Acremont V, Landry P, Mueller I, Pecoud A, Genton B. Clinical and laboratory predictors of imported malaria in an outpatient setting: an aid to medical decision making in returning travelers with fever. Am J Trop Med Hyg 2002;66:481-6.

18 Bottieau E, Clerinx J, Colebunders R, Van den Enden E, Wouters R, Demey H, et al. Selective ambulatory management of imported falciparum malaria: a 5 -year prospective study. Eur J Clin Microbiol Infect Dis 2007;26:181-8.

19 Kiang KM, Bryant PA, Shingadia D, Ladhani S, Steer AC, Burgner D. The treatment of imported malaria in children: an update. Arch Dis Child Educ Pract Ed 2013;98:7-15.

20 Dondorp A, Nosten F, Stepniewska K, Day N, White N, South East Asian Quinine Artesunate Malaria Trial (SEAQUAMAT) group. Artesunate versus quinine for treatment of severe falciparum malaria: a randomised trial. Lancet 2005;366:717-25.

21 Dondorp AM, Fanello Cl, Hendriksen ICE, Gomes E, Seni A, Chhaganlal KD, et al. Artesunate versus quinine in the treatment of severe falciparum malaria in African children (AQUAMAT): an open-label, randomised trial. Lancet 2010;376:1647-57.

22 British Medical Association, Royal Pharmaceutical Society of Great Britain. British national formulary. London: BMA, RPS, 2013:422, 428. (No 65.)

Accepted: 3 May 2013

Cite this as: $B M J$ 2013;346: $\mathfrak{f} 3214$

\section{Related links}

\section{bmj.com/archive}

Previous articles in this series

- Spontaneous oesophageal rupture (2013;346:f3095)

- Pelvic inflammatory disease (2013;346:f3189)

- Colorectal cancer (2013;346:f3172)

- Acute leg ischaemia (2013;346:f2681)

- Delirium in older adults (2013;346:f2031)

C BMJ Publishing Group Ltd 2013 


\section{Key points}

- If patients have fever, history of fever, or flu-like symptoms, always ask about travel to a malaria endemic country within the past year

- If malaria is suspected, request urgent thick and thin malaria films (three negative films results on consecutive days are needed to exclude the diagnosis) and a full blood count (thrombocytopaenia is common in acute malaria)

- If there are any signs of severe malaria, admit as an emergency 